\title{
"SABÍAMOS QUE ACÁ HABÍA HABIDO UNA LUCHA FUERTE Y DURA PARA QUIENES HABÍAN HECHO ESA LUCHA, PERO LO CONSIGUIERON (...) ENTONCES ¿POR QUÉ NO NOSOTROS?" CULTURA OBRERA Y TRADICIÓN EN EL TESTIMONIO DE BEBA
}

\author{
"WE KNEW THAT HERE HAD BEEN A STRONG FIGHT \\ FOR THOSE WHO HAD FOUGHT, BUT THEY GOT IT (...) \\ SO WHY NOT US?'LABOR CULTURE AND TRADITION IN \\ BEBA'S TESTIMONY
}

Alejandra Pisani*

Resumen: El artículo propone el análisis de una historia de vida con el objetivo de rastrear las pautas culturales que operan en el relato. Se trata de la historia de Beba quien nació en 1944 en Santa Lucía, Tucumán, proviene de una familia obrera ligada al trabajo en el azúcar e inició su trayectoria militante en el marco de las acciones contra las políticas socioeconómicas implementadas por la dictadura del general Juan Carlos Onganía a partir de 1966. Hacia principios de la década de 1970 participó de las luchas del Sindicato de Obreros Municipales de Famaillá donde se vincularía primero con el Peronismo de Base y luego con el Partido Revolucionario de los Trabajadores - Ejército Revolucionario del Pueblo. El análisis apunta a visibilizar una tradición obrera contestataria en el relato e identificar el rol desempeñado por esa tradición en los sentidos que la entrevistada atribuye a su propia experiencia; se exploran algunas de las pautas culturales que subyacen a la narración y el modo en que las mismas operaron en las opciones político-partidarias de la entrevistada y, finalmente, se indaga acerca de las estructuras de sentimiento que se configuran en y desde la tradición y las pautas culturales antes mencionadas. Esta propuesta se enmarca en el interrogante acerca de la relación entre la experiencia, la cultura y la conciencia de clase que guía una investigación en curso, cuyo objetivo es caracterizar la relación entre la clase obrera azucarera tucumana y el PRT-ERP 
en el proceso de lucha de clases desarrollado en Tucumán entre 1966 y 1975.

Palabras-clave: cultura, estructuras de sentimiento, conciencia, tradición.

* Becaria Conicet / Docente Universidad de Buenos Aires/CONICET, Argentina. E-mail: 


\begin{abstract}
The purpose of this article is to analyze a life story in order to trace the cultural patterns operating within the life-story. This is the story of Beba, who was born in 1944 in Santa Lucia, Tucumán, in a working class family connected to the sugar industry. She began her activist career in 1966, in the context of the actions taken against economic and social policies that were implemented by the dictatorship of General Juan Carlos Onganía. By the early 1970s, Beba participated in the disputes of the Municipal Workers Union of Famaillá, where she would first be linked with the Peronismo de Base and then with the PRT-ERP. This analysis aims to shed light on the contestatory worker's tradition within the story and to identify the role that has been played through this tradition in accordance with what the interviewee attributes to her own experience. An analysis of some of the cultural patterns that underlie the story is carried out, as well as an inquiry on the way they influenced the political and partisan options of the interviewee. Finally, the structures of feeling that are configured in and from the tradition and the cultural patterns mentioned above are examined. This approach is part of the query on the relation between experience, culture and class consciousness that guides an ongoing investigation. The goal of said investigation is to characterize the relationship between the working class from the sugar industry in Tucumán and the PRT-ERP during the class warfare that took place in Tucumán between 1966 and 1975.
\end{abstract}

Keywords: culture, structures of feeling, conscience, tradition.

En los últimos años se han multiplicado los debates sobre el proceso de radicalización política ocurrido en Argentina durante las décadas de 1960 y 1970. Entre los aspectos más controversiales de esos debates se encuentran las condiciones que hicieron posible la emergencia y el desarrollo de las organizaciones de izquierda en el períodoy las causas de su derrota. Respecto de estos problemas es posible observar que en la mayoría de los argumentos existe una cierta coherencia entre la caracterización sobre la inserción de clase de las organizaciones políticas y las explicaciones acerca de su derrota. Así, las investigaciones que ubican el desarrollo de dichas organizaciones como un fenómeno de clases medias desencantadas con el peronismo y fuertemente influenciadas por el contexto internacional, explican su derrota a partir de un aislamiento respecto de las masas populares originadoen su interpretación errónea sobre los niveles de conciencia alcanzados por estos sectores. De manera complementaria, aquellas investigaciones que ubican a las organizaciones de izquierda como una expresión de la sociedad de su época y ponen énfasis en la articulación de las mismas con la clase obrera, explican su derrota a partir de la dificultad de establecer diagnósticos adecuados respecto de las fuerzas sociales a las que se enfrentaban. De este modo, la relación 
entre las organizaciones políticas de izquierda y la clase obrera se ubica como uno de los puntos nodales de los debates, haciendo que la caracterización de la clase obrera en cuanto a sus formas de conciencia en el período ocupe un lugar central tanto en los argumentos reivindicativos como críticos hacia las organizaciones de izquierda, en particular hacia aquellas que optaron por la lucha armada.

En relación con esta problemática es posible plantear un conjunto de interrogantes vinculados a la caracterización de la conciencia de clase obrera: ¿se puede "medir" la conciencia de clase?, ¿es posible hablar de "grados" o "niveles" sucesivos de conciencia? o más bien habría que pensar en formas cualitativamente diferentes y no necesariamente evolutivas o lineales. ¿Es válido comparar las formas de conciencia de diferentes sectores de la clase obrera? y en este último caso ¿es conveniente establecer una gradación jerárquica de las diferentes formas de conciencia o resultaría más fructífero estudiar comparativamente los procesos que hicieron a la constitución del conjunto dinámico de significaciones que las constituyen? Sin pretender agotar este complejo problema, la hipótesis general que guía el presente trabajo es que la conciencia de clase asume formas cualitativamente diferentes que pueden ser interpretadas en función de las pautas culturales a través de las cuales los trabajadores otorgan sentido a su propia situación en relación a la de otros grupos sociales. En otras palabras, consideramos que la cultura obrera, entendida como un proceso "ordinario", puede ser pensada como una vía de acceso al estudio de la conciencia de clase en tanto constituye uno de los espacios que permite (o no) la resolución de las contradicciones estructurales en la confrontación social. En este sentido, cualquier forma de conciencia, por incipiente que sea, supone la delimitación de un "nosotros" frente a un "otros" cuyos fundamentos primarios son la experiencia cotidiana de la clase y una percepción acerca de las diferencias entre sus propias condiciones de vida y las de los otros grupos sociales a los que está ligada su actividad. Tomando como horizonte estas cuestiones, el presente escrito propone el análisis de un testimonio bajo el supuesto que la exploración de los procesos subjetivos de politización y la indagación acerca de las estructuras de sentimiento y las pautas culturales puestas en juego en dichos procesos pueden aportar a complejizar la mirada sobre el problema planteado. Se ha seleccionado el testimonio de Beba, utilizando como fuentes dos entrevistas realizadas por el Grupo de Investigación sobre el Genocidio en Tucumán (GIGET) ${ }^{2}$ en el marco del trabajo que desde 2005 venimos desarrollando en el sur tucumano. Beba nació en 1944 en Santa Lucía, Tucumán, proviene de una familia obrera ligada al trabajo en el azúcar. Su padre y su tío fueron dirigentes gremiales y participaron del proceso de lucha que dio lugar a la conformación de los sindicatos azucareros y de la Federación Obrera Tucumana de la Industria Azucarera (FOTIA) hacia mediados de la década de 1940. Las primeras 
experiencias de lucha de la entrevistada se produjeron en el marco de las acciones contra las políticas de racionalización económica impulsadas por la dictadura del general Juan Carlos Onganía a partir de junio de 1966. La implementación de estas medidas generó fuertes resistencias por parte de la clase obrera azucarera pero luego de un largo proceso que llevó al desgaste y a la fragmentación de la clase, condujo al cierre de 11 de los 27 ingenios que funcionaban en Tucumán generando un fuerte aumento de las tasas de desocupación y una profunda retracción del aparato productivo provincial.

Hacia finales de la década de 1960, Beba y su familia se trasladaron a Famaillá donde ya estaba radicado su tío, Juan Olmos. Este último, luego del cierre del ingenio Mercedes, donde trabajaba, consiguió empleo en la Municipalidad de esa localidad. Allí encabezó el proceso de construcción del Sindicato de Obreros Municipales de Famaillá y las luchas en pos de la obtención de la personería gremial de dicho sindicato. A partir de fines de la década de 1960, y en el contexto de un fuerte proceso de debilitamiento del movimiento obrero azucarero, este sindicato se convirtió en uno de los principales espacios de articulación de las luchas a nivel local. Beba inició su militancia política en este espacio, primero vinculada al Peronismo de Base (PB) y luego al Partido Revolucionario de los Trabajadores - Ejército Revolucionario del Pueblo (PRT-ERP)

Entre 1973 y 1974, junto a un grupo de militantes peronistas nucleados en este sindicato, estableció sus primeras vinculaciones con el PRT-ERP. Cuando se instaló la Compañía de Monte Ramón Rosa Jiménez en la zona, este grupo fue una importante base de apoyo a la guerrilla. Hacia 1974 ya había comenzado a operar la sección local de la Triple $\mathrm{A}^{3}$, a través de la Juventud Peronista de la República Argentina en articulación con el entonces intendente Julio Saracho. A ellos se les atribuye el atentado que el 31 de octubre de 1974 terminó con la vida de Juan Olmos, tío de Beba, por entonces secretario general del Sindicato de Obreros Municipales de Famaillá. Durante el mismo año, primero la Policía Federal y luego el Ejército realizaron dos "operativos antiguerrilleros" en la zona. Según cuentan los vecinos, a partir de entonces la Policía Federal ocupó la Escuelita de Famaillá, que al año siguiente sería convertida en el primer Centro Clandestino de Detención del país. A partir de 1975, se instaló en Famaillá la sede del Comando Táctico que dirigía el Operativo Independencia. El Ejército desplegó en la zona un verdadero "escenario de guerra", instaló al menos diez dispositivos militares, estableció un estricto control de circulación de personas y mercancías en la zona y asumió el control directo o indirecto de las principales organizaciones estatales y civiles del departamento. A partir de 1976, funcionó en el departamento la principal base militar de la zona sur de Tucumán y cabecera del circuito represivo de la misma zona: el ex ingenio Nueva Baviera.

A principios de la década de 1980, un grupo reducido de personas 
-entre las que se encontraban familiares de Beba- tomó contacto con organismos de derechos humanos que funcionaban en la capital tucumana. A través de ellos se hicieron luego algunas denuncias ante la CONADEP ${ }^{4}$, la mayor parte de las cuales corresponden a casos de desapariciones forzadas. Luego de esa iniciativa, que duró poco tiempo e incluyó sólo a algunas familias, un fuerte manto de silencio se instaló en la población. Este silencio adquiere significación en el contexto pos-dictatorial de la provincia signado por la emergencia y consolidación del bussismo ${ }^{5}$ como fuerza política y la convivencia cotidiana con represores. Ambos factores tienen como condición de posibilidad la impunidad, y constituyen elementos centrales a la hora de pensar la persistencia del miedo sobre el cual se montó el silencio.

La primera de las entrevistas que utilizamos como fuente para este trabajo fue realizada en 2006, durante la primera etapa de trabajo de campo del GIGET en Famaillá, en un contexto en el que la declinación del bussismo como fuerza política en la provincia y la anulación de las leyes de impunidad favorecieron la puesta en palabra de las experiencias del pasado. Beba fue uno de nuestros primeros contactos en la zona y desde ese momento ha sido una persona clave para el desarrollo de nuestro trabajo. Nos abrió las puertas de su casa, facilitó el contacto con sus compañeros de militancia, familiares y vecinos para la realización de entrevistas y participó activamente en la organización de diversas actividades. Con el tiempo hemos construido una relación de amistad y confianza. La segunda entrevista fue realizada en 2012 en el marco de las actividades realizadas por el GIGET en relación a la señalización del ex Centro Clandestino de Detención Escuelita de Famaillá. Este relato ha sido construido en un contexto muy diferente del anterior en el cual la señalización antes mencionada puede ser leída como la materialización de un proceso de visibilización de las luchas populares de las décadas de 1960 y 1970 y del carácter genocida de prácticas desplegadas durante el Operativo Independencia.

En ambos casos el relato de Beba tiene muchos matices, en algunos momentos piensa antes de responder a nuestras preguntas, habla de modo pausado y hace un esfuerzo por recordar datos precisos, fechas y nombres; en otros momentos es enfática y pasional, se entusiasma contando experiencias pasadas y criticando situaciones actuales. Abundan las risas cómplices y las alusiones implícitas a hechos y situaciones narrados con el grabador apagado que no está dispuesta a referir explícitamente durante la entrevista. A lo largo de estos años, y como resultado de un complejo proceso en el que intervinieron múltiples factores, el relato de Beba se fue modificando. Quizás este cambio refleje el carácter dinámico de la memoria y su relación con los procesos sociales en el marco de las cuales se la convoca, quizás sea el resultado de la construcción de un vínculo de confianza con quienes la entrevistábamos o, más probablemente, sea el producto de una conjunción de ambos aspectos. 
Lo cierto es que entre la primera y la última entrevista podemos observar algunos cambios en la perspectiva desde la cual narra algunos de los hechos más importantes de su vida y la de su familia, el más notable, aunque no el único, es el reconocimiento explícito de su vinculación con el PRT-ERP.

Existen también continuidades entre ambos relatos, una de las más significativas es la constante ida y vuelta entre la narración de procesos sociohistóricos y de su propia experiencia subjetiva en el marco de estos procesos. Beba nos cuenta una historia "en perspectiva" en la cual sus vivencias subjetivas adquieren sentido en el marco de procesos sociales generales $\mathrm{y}$, al mismo tiempo, estos procesos son narrados y explicados desde una perspectiva centrada en su propia experiencia vital. Otro elemento común a ambas entrevistas es la asunción de un punto de vista colectivo en el relato. $\mathrm{La}$ entrevistada responde a nuestras preguntas aludiendo a un "nosotros", habla poco de ella en primera persona del singular. Este "nosotros" no siempre refiere al mismo colectivo, dependiendo del contexto puede funcionar como una referencia familiar, político partidaria o de clase e incluso, frecuentemente, estos sentidos aparecen superpuestos. Ambos aspectos aparecen expresados en el relato acerca de las luchas contra la política de cierre de los ingenios azucareros impulsada por la dictadura de Onganía en 1966, una experiencia a la que la entrevistada atribuye gran importancia en ambas entrevistas.

Beba: Esa es la historia de cómo comienzan a formarse los gremios en los ingenios. Como bien se sabe, la historia ésta que se habla del familiar, de esas épocas, de los ingenios, que eran muy estrictos, muy restringidas las visitas familiares... A nosotros nos contaba mi papá que la forma en que se vivía era una forma totalmente, si se puede decir, de esclavitud. Y de ahí es que ellos, ya cansados de todos esos martirios... Incluso dicen que cuando una persona, un niño más que todo -porque siempre los niños son los que hacen las travesuras- se levantaba una caña eran castigados. En ese entonces dicen que a los padres ya los levantaban y los ponían en unos vagones, como del tren, y se los llevaban y los traían para el lugar ese de Acheral y los dejaban ahí... tengan o no como vivir. Fue una época bastante dura, bastante... Y de esa forma ya la gente comenzó a organizarse para formar los sindicatos. Contaban que de noche salían ellos, se iban de noche a veces. El viejito, que era el tío de mi papá, iba a caballo y los esperaba de noche y los montaba y los llevaba hasta que se reunían (...)

Pregunta: Usted viene de la historia de su papá... Beba: Claro, ya de la historia esa... nosotros prácticamente 
no la hemos vivido, sino que nos la contaban. Nosotros ya teníamos en mente lo que era la vida dura, la vida de sacrificios, de tener que vivir así... una vida de esclavitud, así lo tomamos nosotros. Prácticamente uno no la ha conocido a esa vida... porque creo que en ese tiempo eran mis primeros hermanos. Nosotros somos siete hermanos, nosotros somos los tres últimos. Y después que ya se consiguieron los gremios, porque antes los gremios eran sagrados, se los respetaba... una vez que ya vino el gobierno de Perón -que fue del año '45- entonces, ahí, se puso la Ley de Trabajo, ya había leyes que por medio del gremialista se respetaban. Y el obrero era bastante... bastante que se lo respetaba. Le digo más, mi papá había trabajado en el ingenio de acá, él se fue porque... tenía mejores posibilidades allá, ya me imagino como habrán sido acá... Al poco tiempo, después que se organizan los gremios, todas esas cosas, ya la gente ha comenzado a tener la participación también... Porque al poco tiempo a él lo han empezado a ascender, le han dado mejores viviendas y una serie de cosas. Le digo más, mi papá después dejó el gremio. Cuando ya se ha comenzado, en el año ' 60 , que se comenzó con la persecución también... con los ingenios que se cerraban y esas cosas. Pero a él ya lo habían puesto como administrativo... Aparte de eso, él andaba ya enfermo, ya bueno... la lucha había sido dura también... Y bueno, él ahí, en esa parte ya estaba. Aparte de eso él era una persona... bastante inteligente. Ya la situación cambiante que había... Como él decía siempre, como todo padre "queremos lo mejor para nuestros hijos", hoy hay muchas mejores posibilidades. Ahí él deja el gremio, incluso los mismos compañeros del gremio lo habían aconsejado que acepte lo que a él le correspondía, por su lucha, por su trabajo, porque era buen hombre. Y bueno, pasó a la parte administrativa, él se jubiló así. Pero ya había hecho... con los otros compañeros, ya habían hecho la lucha. Él ya había conseguido lo que él quería, no sólo para él... Porque después allá teníamos casas que no nos costaban. Todo, las viviendas gratis, teníamos luz, un bienestar, y todo se debía a la lucha esa que se había hecho. Y después comenzaron de vuelta en el año ' 60 , sesenta y algo que se comenzaron a cerrar los ingenios. Ahí yo ya tengo algo... siendo joven pero ya tenía la conciencia de lo que era la lucha, de lo que se luchaba, de lo que se sufría. Se comenzó también porque se los perseguía a los dirigentes... Incluso yendo a FOTIA -que se iban a reunir todos los de los ingenios- murió la compañera 
Hilda Guerrero ${ }^{6}$, en esa lucha por el cierre de los ingenios. Después ya viene... cuando lo teníamos de gobernador a Gelsi, él era radical... ya entonces estábamos con las luchas...

Vecino: En ese tiempo los han corrido con mangueras de agua a los cañeros chicos...

Beba: A todos, todos eran... eran épocas que ya la dureza comenzaba y ya la gente joven. Le digo más, nosotros, que nosotros teníamos no una experiencia vivida sino una experiencia por lo que nos habían contado los que eran de aquellas épocas. Entonces uno, como joven, temía volver a eso. Y a pesar que una era joven teníamos un bienestar, porque se había conseguido. Entonces temíamos nosotros por el futuro de nosotros mismos, de caer en lo anterior. Eso te daba fuerza, te daba fuerza a pesar de que eras joven, de decir "sí, yo me voy con aquellas referentes". El caso de Hilda que era vecina de nosotros, una mujer con mucho temple, mucho espíritu... como que te contagiaba eso y te decía "vamos, nosotros vamos a decir que tenemos clase esto, o de la escuela o algo así" y nos íbamos caminando hasta la FOTIA, desde Santa Lucía dábamos vuelta y pasábamos por Bella Vista. Ahí había otros compañeros que nos esperaban. Éramos jóvenes, ni siquiera nuestros padres sabían... Pero era eso, que nosotros no queríamos volver a lo que había antes, lo del perro familiar y toda esa historia. Y de ahí comienza... ya es, parece que... que ya eso... eso queda. Yo, por ejemplo, ahora... a mi hija le hablo mucho. Yo tengo una sola hija, a ella le converso, le explico, le cuento... No sé si ella lo siente o lo ve como yo lo he vivido, como yo lo he sentido y como a mí me ha atrapado eso... Yo tampoco la voy a exigir a ella, pero yo le cuento todo lo que ha sido antes y que si nosotros no cuidamos este valor divino que tenemos de la democracia podemos llegar a volver a ser lo que ha sido antes. Por eso yo -como les dije a ellos- sinceramente había dicho "yo política nunca más"... política... pero sí, he dicho "si yo tengo que estar... prefiero morir de parada en una lucha y no postrada en una cama"

En el relato de Beba el reconocimiento estatal de los sindicatos de ingenio y la promulgación de las leyes laborales durante el primer gobierno peronista aparecen como un punto de inflexión en las condiciones de vida de los trabajadores. Este cambio es significado como una conquista de los trabajadores, como el resultado de un largo proceso de organización y lucha 
que permitió el paso de una "vida de esclavitud" a una vida de respeto para el obrero. La entrevistada cuenta que ella no vivió esa "vida dura" pero la conoció a través de lo que su padre le contaba y que, a través de esos relatos, conoció también las luchas que llevaron a su transformación. En este "saber" la propia biografía, la historia familiar y la historia del sector de la clase obrera a la que pertenece aparecen profundamente articulados. El conocimiento de las condiciones de explotación y sometimiento padecidas por su familia y por el resto de los trabajadores azucareros antes del reconocimiento legal de los sindicatos cobran relevancia entre los sentidos que atribuye a su propia acción: la defensa de las conquistas logradas por las generaciones anteriores aparece como el motor de la acción, como aquello que le "daba fuerzas" para participar de las medidas de lucha que se estaban llevando a cabo. Estas acciones, a su vez, son presentadas como un modo de no volver a la "vida de sacrificios" que conocieron sus abuelos, padres y hermanos. De forma complementaria, la apropiación de la experiencia de lucha que llevó al fin de esa "vida de esclavitud" pareciera otorgar una noción de la propia potencia transformadora. De este modo, la historia de vida que Beba va construyendo se inscribe en una historia que excede cronológicamente a la de su propia generación y en la cual las experiencias de lucha previas aparecen como una constatación de la posibilidad de transformar la realidad a través de la acción colectiva. Dentro de esta historia sus prácticas subjetivas adquieren sentido en el marco de un proceso de confrontación histórico en el cual las experiencias previas se asumen como propias y donde las acciones e iniciativas obreras de las décadas de 1960 y 1970 son presentadas como un momento de una historia de lucha que se remonta hasta antes del primer gobierno peronista y continúa hasta el presente. Este modo de concebir la conformación y la historia del propio campo produce, en el mismo movimiento, una historización de las fuerzas a las que se enfrentaron. En el fragmento antes citado esto se expresa en el establecimiento de una continuidad entre el sometimiento del obrero a condiciones de opresión durante el período previo al peronismo y la "persecución y asesinato de dirigentes gremiales" en la década del sesenta. En este sentido, la expresión "comenzaron de vuelta en el año sesenta" supone una equiparación entre los intereses encarnados por los distintos grupos sociales que, a lo largo de la historia, llevaron adelante estas prácticas.

A través de estos elementos el relato va configurando una continuidad temporal pasado-presente-futuro en la cual la trasmisión oral aparece como el hilo conductor de una tradición obrera asentada en valores y percepciones contestatarios. Cabe aclarar que, siguiendo los planteos de Raymond Williams, entendemos aquí que la tradición constituye un proceso irreductible a la mera supervivencia de un pasado inerte. Toda tradición supone una construcción activa que permite otorgar sentido a una serie de continuidades prácticas que son directamente experimentadas por los sujetos. En el testimonio que aquí 
analizamos esas continuidades están fuertemente ligadas a una experiencia cotidiana marcada por condiciones de clase. Esa experiencia es percibida y significada en términos de una contraposición entre los propios intereses y los de otros grupos sociales. Se configura así una noción de "nosotros contra otros" que permite establecer un sentido de continuidad entre la experiencia de lucha de la propia generación y la de las anteriores. Esta oposición no es el resultado de una racionalización de la experiencia ni tiene el grado de articulación propio de una ideología formal, se trata más bien de una "estructura de sentimiento", de valores y percepciones que se hallan "en solución", que no necesariamente son resultado de una operación consciente pero que han tenido (y tienen) importantes consecuencias en los procesos de definición e identificación cultural, política y social de la entrevistada. Así parece expresarlo cuando al narrar sus primeros pasos en la militancia se refiere a algo "que queda" en alusión a la experiencia de su padre y abuelo o cuando, en otros momentos de las entrevistas, comenta que su predisposición a participar de las iniciativas y acciones obreras es "algo que viene de familia". Si bien la entrevistada no atribuye un contenido definido a "eso" que queda, en el contexto del relato aparece asociado a un conjunto de valores y percepciones críticas que circulan a través de la trasmisión oral de las experiencias de lucha. Beba los recibió a través de los relatos de su padre y se los transmite a su hija al contarle su propia experiencia.

Estos valores y percepciones no necesariamente se plantean explícitamente, pareciera más bien que constituyen el sustrato desde el cual se estructura el relato, el marco de referencia a través del cual los hechos narrados adquieren sentido. Vistos de este modo, ese conjunto de valores y percepciones cambiantes tienen en común el hecho de proporcionar una clave de lectura de la realidad basada en la noción de "nosotros contra otros" antes mencionada. Esta noción, resignificada en función de los conflictos de cada coyuntura, permite establecer un sentido de continuidad entre las prácticas de lucha de las que la entrevistada formó parte y las conocidas por ella a través de la trasmisión oral. En otras palabras, ese sentido de continuidad se configura en torno a una noción de "nosotros contra otros" que opera fuertemente en el relato otorgando un marco de inteligibilidad común a los hechos del pasado y del presente que habilita la posibilidad de pensar el futuro en términos de transformación.

En la narración acerca del proceso de conformación de los sindicatos azucareros, como hemos visto, la noción de "nosotros contra otros" opera de modo tal que permite significar la promulgación de derechos obreros, el reconocimiento estatal de los sindicatos y el mejoramiento en las condiciones de vida de los trabajadores en términos de "conquista", es decir, como resultado de un proceso de organización y lucha de larga data que hacia 1944 condensa en la constitución de la FOTIA y en una serie de transformaciones 
sustanciales en las condiciones de vida y de trabajo de los obreros azucareros. Esas luchas y conquistas aparecen en el relato como un elemento articulador de sentido de su propia experiencia:

Beba: Después de la muerte de Hilda, todavía estábamos en Santa Lucía, la persecución era como yo decía. Después volvemos acá ${ }^{8}$, prácticamente fue en el año sesenta y... También era una lucha cultural, también había dos partes. Desgraciadamente siempre nos damos con que estábamos divididos en el peronismo. ¿Por qué? Porque siempre estaba la parte derecha y siempre estábamos los de la izquierda. Nosotros no aceptábamos la parte derecha. Acá en Famaillá estaba la señora esta... Soria, después estaba Sánchez Toranzo en San Miguel... que ésos eran, como se dice vulgarmente, "los capos". Y aquí, la persecución que nosotros teníamos... Aquí cuando era la lucha, nosotros trabajábamos acá -en el tiempo de Saracho- con el gremio, con el sindicato de Juan Olmos, que era mi tío. Él ha sido un tipo muy luchador por sus compañeros, por la clase obrera. Él venía del ingenio Mercedes, aparte tenía un hermano, Desiderio, que también ha sido... prácticamente esto viene de familia, ya viene esto de familia. Y acá cuando él entra y... Porque ellos en la época de antes trabajaban por su cuenta. En esa época no había los camiones, las flotas de camiones... En ese entonces vivía mi abuelo, ellos tenían flotas pero de carros... después murió mi abuelo, pasaron cosas... y siempre él era un tipo de lucha... y bueno, se perdió todo eso..

Pregunta: ¿Cómo decide armar el sindicato Olmos?

Beba: Él viene para acá -como le cuento- cuando ya queda él sin eso, cuando cambia la situación, él se viene para acá. Le dan un trabajo en la municipalidad. Entonces, cuando él comienza a trabajar en la municipalidad, veía que las cosas de la municipalidad no eran como tenían que ser. Entonces el tipo comienza a hacer la organización, a organizarse como gremio. Creo que era en el año '60. Entonces él comienza a formar el sindicato... Había, sí que había pero eran sindicatos que estaban, como se dice vulgarmente, "al aire", porque no tenían personería y no se hacían respetar como tenía que ser. Entonces el tipo comienza, entra a trabajar ahí, en la municipalidad. Él ha entrado como un peón, con la categoría mínima. Entonces el tipo ha comenzado la lucha, ha comenzado a hablarles a los compañeros. Había incluso compañeros que eran de allá, de donde él vivía, del campo, de Monte Grande, 
que lo conocían. Se organizaron, se luchó, se hicieron muchas cosas para conseguir sacar la personería... Estaba él, estaba el doctor éste... Román que era abogado. Así, gente, porque él siempre ha estado en el gremio. Incluso él... yo era más chica, pero sí sentía las conversaciones cuando él trabajaba en el campo, había viajado a Buenos Aires, que había estado con... bueno. Y de ahí él empieza a organizarse acá, en Famaillá. Por supuesto los compañeros lo apoyan y sale como secretario general. De ahí se comenzó a luchar por los derechos del trabajador, se formó. Él aparte del gremio, por supuesto, también iba inmiscuida la política. Entonces se hace una coordinadora -que ahí era donde estaba el doctor Anido- nos formamos ahí la juventud... Y estaban ellos y nosotros apoyábamos... bueno, apoyábamos lo que teníamos que apoyar y lo que no teníamos que apoyar, éramos bastante... a veces también había discordia, como en toda cosa, que a veces un mal entendido, bueno, discusiones.

Él fue una persona muy querida, fue muy humanitario, luchaba mucho por los obreros. Eso es lo que yo veía cuando hacían las tomas acá. Yo decía "¿cómo van a hacer una toma así? Armar una carpa, sufrir como estaban sufriendo, más de lo que ellos sufrían porque los manoseaban hablemos así porque es la realidad-. Las tomas que se hacían eran tomas... Siempre había uno -como nos pasaba a nosotros en la lucha también- que decía "sí, yo estoy con ustedes" y resulta que era de la otra parte, llevaba lo que... Había una persona de esas, un infiltrado. Entonces decían "La entrada que ustedes tienen la van a hacer"... Nosotros hacíamos las tomas pasivas, pero eran tomas que nosotros íbamos, nos sentábamos en el escritorio del intendente y decíamos "señor intendente acá no va a entrar hasta que usted no cumpla con los derechos del obrero". Y la otra parte, que estaba con ellos, ya venía con palos, con piedras, botellas rotas, pero nosotros estábamos ahí. Y así conseguíamos, así se conseguía y así eran las luchas. Aparte, había compañeros que estaban en muy mala situación y la casa de él estaba abierta. Lo mismo que nosotros, con mi hermano, mi papá nos apoyaba un montón a nosotros porque él ha sido un hombre de lucha. ${ }^{10}$

La familia de Beba, como la mayoría de la familias obreras tucumanas vinculadas al trabajo en el azúcar, sufrió el impacto de las políticas implementadas por la dictadura del general Juan Carlos Onganía a partir de junio de 1966. Este conjunto de medidas tenía como objetivo declarado la 
racionalización y diversificación de la industria local pero, en los hechos, implicó una retracción forzada de la producción azucarera. La dictadura decidió intervenir y cerrar los ingenios en teoría menos eficientes, regular la producción de caña a partir de la expropiación de los cupos de producción a los pequeños productores, mantener cupos de producción por ingenio y poner en marcha un plan de incentivos fiscales para la radicación de nuevas industrias. Como consecuencia de estas políticas entre 1966 y 1968 se produjo el cierre de 11 de los 27 ingenios que funcionaban en la provincia, una reducción de personal de los 16 ingenios restantes y una contracción del $41 \%$ del aparato productivo provincial que fue acompañada por un importante retroceso demográfico y por un aumento de las tasas de mortalidad infantil y de analfabetismo que afectaron especialmente a las áreas azucareras ${ }^{11}$.

En el relato de Beba la implementación de estas políticas es ubicada como un punto de inflexión respecto de las condiciones de trabajo de su familia y de las condiciones de lucha de clase de la que ella formaba parte. Sin embargo, esta transformación no es significada como una clausura de la capacidad de organización y acción de los trabajadores sino como un cambio en las condiciones de su desarrollo. La entrevistada destaca esta continuidad en su descripción del proceso de constitución del Sindicato de Obreros Municipales de Famaillá a través del énfasis puesto en la trayectoria de lucha de su tío, Juan Olmos, en el ingenio Mercedes y cuando se refiere a los compañeros que conociendo la trayectoria de Olmos deciden apoyarlo. A través de estos elementos el relato va configurando una línea de continuidad entre las luchas previas y posteriores al cierre de los ingenios que se estructura en torno a la figura de su tío. La experiencia previa de Olmos pareciera jugar como un elemento que favoreció su capacidad organizativa, quizás porque le brindaba una perspectiva adecuada para percibir los problemas de los trabajadores y plantear alternativas de solución a esos problemas. Otro elemento que adquiere relevancia en el relato es el énfasis puesto en el hecho de que Olmos ingresó a trabajar en la municipalidad con la "categoría mínima", como "peón", esta posición aparece asociada a la idea de honestidad, en este sentido Beba remarca una y otra vez a lo largo de la entrevista que tanto Olmos como el resto de su familia nacieron "pobres" y así permanecieron.

En el relato es posible observar además una segunda línea de continuidad vinculada a los objetivos de la lucha. La misma aparece expresada en la relación que se establece entre la necesidad de obtener la personería gremial del Sindicato de Obreros Municipales y la percepción acerca de que "las cosas en la municipalidad no eran como tenían que ser". Esta última afirmación aparece asociada a la falta de respeto al obrero y a sus derechos, en este sentido contiene una valoración prescriptiva acerca de las funciones que competen al sindicato. Éste no funciona simplemente para garantizar el cumplimiento de la normativa vigente en torno al trabajo sino que es visto 
implícitamente como el encargado de limitar el poder y los abusos de las clases dominantes garantizando así la dignidad del obrero en un ámbito que pareciera exceder al del lugar de trabajo alcanzando al conjunto de la vida de los trabajadores. Así como sucedía en la narración acerca de la experiencia de los obreros azucareros, la conformación del Sindicato de Obreros Municipales de Famaillá y su reconocimiento legal son presentados como una conquista obtenida por los trabajadores a través de una lucha. Esta lucha, si bien se desarrolla en condiciones diferentes a las que llevaron a la construcción de los sindicatos de ingenio, tiene en común con ella el hecho de enfrentarse a los sectores que se beneficiaban negando a los obreros sus derechos. Esta última idea aparece reforzada en su caracterización del contexto en el que se desarrollan las acciones de los trabajadores municipales, cuando sostiene que al interior del peronismo "también había dos partes": la derecha, a la que asocia las persecuciones sufridas por los trabajadores; y la izquierda, a la que reconoce como ámbito de pertenencia, describe como capaz de enfrentarse a sujetos poderosos como el intendente y asocia al "humanitarismo", a la solidaridad y a la "lucha por los obreros".

A través de estos elementos vemos reaparecer la noción de "nosotros contra ellos" a la que referíamos anteriormente, pero resignificada ahora en términos de izquierda versus derecha peronista. Esta oposición opera al mismo tiempo como clave de inteligibilidad de lo social y como elemento explicativo de las opciones políticas tomadas por la entrevistada:

Beba: ...Prácticamente en esa época se forma ya la división esa, comienza ya la división... Ahí sacamos las garras y dijimos "nosotros somos de la izquierda y ustedes son de la derecha". Ellos querían ser pasivos pero no era que eran pasivos sino que ellos tenían otra mentalidad.

Vecino: De día organizaban la paz y de noche te sacaban de la casa.

Beba: Claro, es lo mismo que al obrero. A pesar que estábamos en un gobierno de democracia lo mismo se los perseguía, era un señor que era temible. ¿Por qué? porque ellos estaban trabajando de otra manera. Sabían que Olmos tenía posibilidades de ganar, a pesar que nunca se postuló, él siempre ha sido gremialista, gremialista, gremialista. La lucha de él era el gremio, defender a sus obreros. Pero estábamos nosotros, estaba la otra parte donde estaba realmente el político. Cuando ellos ven eso comienzan a perseguirlo (...) Nosotros no luchábamos para el izquierdista sólo...

Vecino: No estábamos con la Hoz y el Martillo, no estábamos con la teoría de Marx, estábamos con las 
reivindicaciones populares...

Beba: ...claro, en general

Vecino: Y nos pintaban como que nosotros estábamos con el marxismo

Beba: Exactamente

Pregunta: Entonces cuando aparece el Operativo Independencia ustedes estaban dentro de ese espectro político y social aquí en Famaillá.

Beba: Claro, aquí en Famaillá. Nosotros nos organizamos... acá en Famaillá nace desde el gremio de Juan Olmos. Nos reuníamos en la casa de él, ahí nos reuníamos... e incluso nos daban, nos adoctrinaban pero siempre, siempre con la doctrina esa de que nos respetemos. No sólo la lucha era para nosotros, sino que nosotros luchábamos en general, entonces de ahí comienza. Por supuesto, Olmos ya tenía gente conocida... porque él -como digo siempre- ha sido un tipo que le gustaba la política a pesar de que nunca se ha postulado...

Vecino: Venían a dar charlas

Beba: Claro, daban charlas, daban... enseñaban todo. Todo, todo... defensa, enseñaban todo. Ellos venían y nos comenzaron a conversar -por supuesto- muy lento, primero, hasta que tomáramos conciencia. Entonces ¿qué pasa? Nosotros tomamos conciencia y decimos "¿Por qué? si decimos `somos peronistas', hay un sólo líder ¿por qué estamos divididos?" y vemos la parte social y decimos “acá pasa esto". Acá, para nosotros, ellos estaban utilizando el peronismo, vale decir, el fascismo lo utilizaba. Los que realmente estábamos luchando por el líder, con las ideas del líder, éramos nosotros que queríamos hacer la justicia social, la democracia en general. En cambio ellos no, ellos querían su poder... Entonces ahí comenzamos, ahí comienza la juventud.

Vecino: Ellos pensaban heredarlo a Perón

Beba: Entonces decimos "No". Cuando ellos nos hacen ver, nos hablan, y nosotros nos ponemos a pensar y nos ponemos a ver desde la parte social y decimos "si ellos son gente que tienen el poder económico". Ya tenían el poder también. Los jueces, como está ocurriendo ahora. Entonces ¿qué pasa? "Si nos dan una posibilidad para que nosotros luchemos y descartemos esto, bueno, vamos a esto, porque esto es lo nuestro"... Y más que nosotros teníamos la idea ésa de cómo era antes, en las épocas de los ingenios, no queríamos nosotros que eso vuelva. Sabíamos que acá había habido una lucha fuerte y dura para quienes habían hecho esa lucha, pero lo consiguieron. Y nosotros decíamos 


\begin{abstract}
"esa gente iba a caballo, los más viejos iban a caballo y los más jóvenes a pie. Entonces ¿por qué no nosotros?”. Por supuesto que lo estudiamos bien a ver si era la realidad, si nos convenía. Cuando nosotros vimos que era la realidad lo que ellos nos estaban haciendo ver, veíamos nosotros que acá, siendo un pueblo chico, teníamos ya esas diferencias, entonces "No, vamos al frente, luchemos. No dejemos que la vida, que la sociedad retroceda, tenemos que avanzar". Entonces ahí, cuando ya nosotros, nosotros, cuando ya nosotros sentimos, no que nos exigieron, cuando ya nosotros sentimos que queríamos luchar, que queríamos descartar esto, ese poder, bueno, nosotros dijimos "quiero ser un militante". Ellos nos explicaron bien qué era lo que significaba hacerse militante, cuál iba a ser y cómo iba a venir la cosa. Nosotros decidimos a conciencia, a nosotros nadie nos exigió, nadie nos obligó ni nadie nos engañó ${ }^{12}$.
\end{abstract}

Beba caracteriza el contexto en el que comienza su militancia político-partidaria como un momento de agudización de las tensiones entre el peronismo de izquierda y el de derecha en el cual la existencia de un régimen constitucional de gobierno no constituía una garantía del ejercicio de la democracia. Ubica esta coyuntura como un momento de definiciones políticas tanto a nivel colectivo como subjetivo, como un momento de "sacar las garras" y definir posiciones. Esta necesidad aparece directamente vinculada a su caracterización del comportamiento de los sectores vinculados a la derecha peronista que, según la entrevistada, "trabajaban de otra manera", es decir, no asumían explícitamente sus objetivos. A través de estos elementos el relato va definiendo una diferenciación en la cual el propio campo aparece asociado a valores como la solidaridad, el respeto, la justicia social, la verdadera democracia; mientras que el peronismo de derecha es vinculado a la persecución de dirigentes gremiales, al fascismo y al poder económico. Uno de los principales elementos que opera en esta diferenciación son los objetivos de la lucha: mientras que en un caso se trataba de "una lucha en general" en la cual los intereses de los "izquierdistas" y los del campo popular coincidían, en el otro se trataba de una "utilización del peronismo" por parte de los sectores más poderosos de la sociedad que buscaban apropiarse del poder de Perón para utilizarlo en su propio beneficio. Este diagnóstico adquiere un lugar central entre las motivaciones que llevaron a Beba a la militancia político-partidaria que, a su vez, aparece como una vía para hacer realidad los ideales "verdaderamente peronistas" detrás de los cuales se ocultaban los sectores vinculados al poder económico para implementar un proyecto hostil hacia los trabajadores. Otro elemento que opera fuertemente en este sentido es la recuperación de la experiencia de lucha pasada: la coyuntura 
es significada como una situación de amenaza para las conquistas logradas por las generaciones anteriores que sólo podía revertirse a través de la acción colectiva. Esta acción aparece como una forma de impedir que"la vida y la sociedad retrocedan", de "avanzar" hacia nuevas conquistas, mientras que la historia de los trabajadores azucareros funciona como una demostración de que era posible lograrlo.

De este modo, la tradición a la que venimos refiriéndonos permite establecer una continuidad temporal que opera en diferentes niveles: atribuyendo un sentido histórico a la propia práctica de lucha que la ubica como un momento de una confrontación que trasciende a la propia experiencia subjetiva y generacional tanto hacia el pasado como hacia el futuro; otorgando sentido a esa práctica de lucha en términos de necesidad de defender las conquistas del pasado y avanzar en la obtención de otras nuevas; y como constatación histórica de la posibilidad de transformar la realidad a través de la acción colectiva. Esta continuidad se configura a través de la resignificación de ciertas pautas culturales que circulan de generación en generación contenidas en los relatos orales y encuentra anclaje en una percepción que ubica a la realidad como el resultado, siempre en devenir, de una confrontación entre grupos opuestos en sus intereses, valores y formas de vida.

Estos elementos están presentes también en las explicaciones de Beba acerca del proceso que la llevó a vincularse al PRT. En el relato de Beba ni el ingreso al PB ni el paso al PRT marcan un punto de inflexión en su vida. El relato no sigue una estructura lineal en el que la militancia partidaria se presenta como un corte o como un "antes y un después". Lo que aparece es una continuidad en la cual la narración de las experiencias no se organiza en función del espacio de inscripción político-partidario en el que se desarrollaron, sino de ciertos cambios en las correlaciones de fuerza entre un "nosotros" y un "otros" definidos en los términos antes mencionados.

Beba: Claro... lo que yo me pongo a pensar ahora... porque te digo que nunca se me ha dado por decir "¿pero cómo?"... Sí, estábamos, nos reuníamos, todas esas cosas... pero nunca se me ha dado por decir "¿Cómo hemos empezado?", de qué manera, cómo nos hemos insertado ahí... O sea, una forma de... el pillo de Juan Olmos nos iba mentalizando lentamente sin que nos diéramos cuenta... me pongo a ver yo ahora, porque sinceramente te digo, que venían los chicos de la universidad, qué se yo. Y a veces tenían sus reuniones que nosotros no participábamos, al principio. Después si, ya... ¿me entendés?... Entonces por eso te digo que para mí la infiltración ha venido por ahí [risas]. Y nos han trabajado, nos han mentalizado así, 
lentamente, que vos cuando te has dado cuenta decías "ya está". Y yo lo que me acuerdo de este hombre, que no me puedo acordar como se llamaba, pero que había venido con Santillán. Que ha sido la primera vez que mi tío me hace orar a mí. Yo me acuerdo ahora de eso porque yo nunca... una sola vez me han hecho orar con un papel (INAUDIBLE). Y así, bueno, habla Santillán, habla el otro, después ha hablado... ¡Ah! Le tocaba a mi tío y mi tío dice: "No, yo no, ella ahora va a orar, por la juventud, del grupo la juventud". Bueno, me agarró de sorpresa y me he largado. Y yo de ahí saco la conclusión que la cosa ha venido así, porque yo me acuerdo, debe ser que ya algo nos iban... con palabritas que... que no sé, en ese momento. Yo me acuerdo que ahí mi tío viene y me abraza y me dice "éste es mi pollo". Yo me acuerdo que dije que no íbamos a permitir que con el sudor de los trabajadores rieguen el jardín los... los patrones... Entonces es porque ya estaba mentalizada algo, inconscientemente creo... yo me pongo a pensar ahora. Y de ahí ya mi tío me agarró de oradora... Yo de eso me acuerdo y digo, es la forma entonces... los primeros, cómo llegan ellos, es ahí, con los chicos de la universidad. Porque incluso ellos venían y estaban acá ${ }^{13}$.

A nuestra pregunta acerca de sus primeros contactos con el PRT Beba respondió que nunca antes había pensado en eso. Esa inquietud -importante para nosotros- no formaba parte del modo en que ella se pensaba a sí misma, en su historia la politización es vista como una prolongación de su experiencia de vida que sucede casi "naturalmente". Responder a esa pregunta supuso entonces un cambio de perspectiva o, más bien, una forma diferente de evocación y de articulación de sus recuerdos. A partir de esta nueva forma de evocación la militancia aparece íntimamente asociada a los lazos familiares y a un proceso de transformación de sus percepciones y conciencia que ocurrió de modo paulatino, "casi sin darse cuenta" hasta que en un momento apareció condensada en un discurso. El sentido disruptivo de aquel discurso aparece asociado a la aprobación de su tío que, retrospectivamente, viene a resignificar lo que en aquel momento apareció como una acción espontánea. Beba refuerza la idea de su politización como derivación de su experiencia cotidiana cuando, entre risas, nos habla de una "infiltración". Esta expresión no pareciera remitir a un acto engañoso sino más bien a un cierto modo de articulación entre la ideología formal y las prácticas del PRT y su propia subjetividad que operó en un nivel no del todo consciente para ella. Si en algunos momentos remarca que su decisión fue tomada "conscientemente" es para dejar en claro que no fue producto de un engaño ni de una presión, sino la expresión de un "sentimiento", de una necesidad de luchar para "descartar" las condiciones de opresión a la que estaban sometidos los trabajadores. De este modo, el testimonio pareciera indicar que el ingreso de la entrevistada al 
PRT fue menos el resultado de una decisión "racional" basada en un acuerdo con la ideología formalmente postulada por esta organización que un efecto del modo en que ciertas formas de interpelación ideológicas lograron anclar sobre las pautas culturales que formaban parte de su sentido común. En otras palabras, la incorporación al partido pareciera estar vinculada al modo en que ciertas prácticas desplegadas por el partido encontraron anclaje en estructuras de sentimiento clasistas forjadas en la experiencia y trasmitidas intergeneracionalmente a través de la oralidad. En relación con esto resulta significativo que la entrevistada refiera a la condición revolucionaria como algo vinculado a ciertos sentimientos que la acompañan desde el nacimiento.

Pregunta: Volviendo un poco más para atrás... vos estabas en el sindicato, decías que primero estaban en el PB y después que tu tío los iba como... formando digamos Beba: Claro, claro, porque la formación ha salido de ahí. Pregunta: Y también nos decías recién que en un momento se tuvieron que decidir para que lado iban, ¿por qué optaste por el PRT y no por el peronismo de izquierda?

Beba: Sinceramente te digo, nosotros... la izquierda ya venía de antes que estaba dividida... hasta de la época de Evita te podría decir, para mí ella ha sido izquierdista, o sea, revolucionaria. Entonces siempre uno ha tenido esa opción, porque peronista eras porque te lo inculcaban. Vos decías peronismo porque te lo inculcaban. Hemos comenzado trabajando con el PB, como peronistas. Pero siempre nosotros hemos tenido la inclinación esa, siempre hemos renegado de Perón nosotros. Entonces cuando tenés como una oportunidad y cuando ya la mente tuya la trabajás vos y vos empezás a sentir tus sentimientos $\mathrm{y}$ no lo que te han inculcado o lo que has escuchado, entonces bueno, ahí ya tomás conciencia (...) Bueno y de ahí, esa tendencia ya la tenía dentro de... creo que cada individuo nace ya... si tenés todos los sentidos ya nacés con todo... Hay una edad que quizás vos no lo manifestás ni la desarrollás, cuando sos mandada acatás órdenes. Pero cuando vos ya tenés tu edad de desarrollar tu pensamiento, tu sentimiento y de decir "bueno, esto es lo mío", es como la vocación que uno elige. Entonces bueno, decís "esto es, acá estoy y de aquí nadie me saca, que sea lo que Dios quiera. ¿Por qué? Porque yo creo que ésta es la parte que realmente merecemos". Los derechos, como personas, como seres humanos, saber hacer prevalecer los derechos, que hay que lucharlos a los derechos para que no te los arrebaten, y que si no luchas y te quedás con las manos cruzadas, bueno, no sólo uno te los va a venir a arrebatar. 
Entonces ¿qué es lo que tenés que hacer?, tenés que luchar, pelearla, discutirla, enfrentarla y eso es lo que te lleva. Entonces por eso te digo, yo creo que eso de decir "soy izquierdista", "soy revolucionaria" ya nacés vos con eso, es una vocación más en tu vida, porque sino no lo harías ${ }^{14}$.

En este fragmento la incorporación al PRT es presentada como un momento de rearticulación y de exteriorización de toda una serie de sentimientos y pensamientos latentes que se produjo a través de un distanciamiento respecto de la tradición familiar. En este sentido, pareciera ser presentada como una ruptura con ciertos mandatos que le habían sido "inculcados" condicionando sus primeras formas de identificación política hacia el peronismo. Sin embargo, esta idea de "ruptura" entra en tensión con otros elementos más generales en función de los cuales la entrevistada organiza el relato de su historia de vida. Como fue mencionado, la narración de Beba no sigue un orden lineal en el cual su militancia en el PB y en el PRT representan dos etapas claramente diferenciadas, más bien lo que aparece es un orden que encuentra anclaje en ciertos conflictos y en el que tienden a diluirse las fronteras entre sus diferentes espacios de militancia. De este modo, el testimonio pareciera indicar que el ingreso al PRT está más vinculado a la construcción de nuevos sentidos sobre la base de las estructuras de sentimiento compartidas que a un quiebre respecto de la tradición peronista de su familia. En otras palabras, la vinculación al PRT pareciera estar relacionada con una resignificación de la noción de "nosotros contra otros" que constituye el núcleo de la tradición contestataria familiar, producida en el marco de una nueva coyuntura sociopolítica que es percibida como un avance de la derecha que amenaza los derechos conquistados por la clase obrera.

En el relato existen algunos indicios que parecen avalar esta idea, uno de los más importantes está relacionado con ciertas "confusiones" entre las prácticas desplegadas por el PRT y por el PB. Muchas veces Beba responde a nuestras preguntas sobre el PRT refiriendo a acciones desarrolladas por la organización peronista. Es probable que estas confusiones estén relacionadas con ciertas dificultades en la evocación de los recuerdos o con una decisión consciente por parte de la entrevistada destinada a evitar responder a nuestras preguntas, pero también parecen indicar la presencia de un sentido de continuidad entre ambas experiencias. Otro elemento que opera en este sentido es la fuerte presencia en el discurso de términos provenientes del marco ideológico del peronismo a la hora de dar cuenta de su experiencia en el PRT. Uno de los que aparecen con mayor frecuencia y siempre vinculado a los objetivos de la lucha es el de "justicia social": 
Pregunta: $\mathrm{Si}$ yo te preguntara ahora por qué era que luchaban, ¿vos que me respondés?

Beba: Bueno porque queríamos un... Una, se luchaba por los derechos que nos estaban quitando. Otra, porque queríamos un Estado mejor, no sé si una Argentina mejor... por una mejora. Y para defender los derechos, porque nos los estaban quitando, si estaban quitando todo, como que han quitado... muchos derechos se han quitado, tanto del trabajador, como del estudiante, la juventud y todo, hasta de los niños... Entonces todas esas cosas había que pelearlas. ¿Vos viste que en la época de Eva estaban esas colonias de vacaciones, todo eso? Y todas las... Acá en los ingenios había gente de la misma fábrica que decían: "ah, sí, los ingenios se han fundido porque la gente robaba"; pero porque la gente te saque un kilo de azúcar no va a quebrar una fábrica.

Pregunta: ¿Ustedes sólo querían recuperar los derechos perdidos?

Beba: Queríamos recuperar los derechos perdidos y se quería una justicia social... que haya una justicia social ya más colectiva, porque ya eso estaba disperso, ya se estaba viendo, ya había diferencias, ya se estaban notando las diferencias, entonces a eso no queríamos llegar... Te digo que sí, las luchas han sido... han sido luchas fuertes, luchas que... se quería luchar por los derechos, recuperar lo que te han sacado, las fuentes de trabajo. Ya se veía a la gente golondrinar ${ }^{15}$, ya se estaba viendo, ya se notaba la pobreza (...) ya se estaba viendo eso, entonces vos como que te afligías y decías: "no, si acá nos quedamos todos sentados ¿qué va a pasar?, nos van a cavar un hoyo y nos van a tirar ahí, que respires si podés y si no podés respirar bueno, que Dios te ayude”. Entonces tenías que salir ${ }^{16}$.

Cuando le preguntamos acerca de los objetivos de la lucha, Beba refiere a una defensa de los derechos amenazados y a la construcción de un Estado mejor. Estos objetivos eran encarnados no sólo por los trabajadores sino también por "la juventud" y "los estudiantes". Este dato adquiere relevancia si tenemos en cuenta que en esa época los sectores universitarios del PRT habían logrado establecer contactos en la zona a través del Sindicato de Obreros Municipales de Famaillá. Se configura de esta manera un "nosotros" amplio que incluye a otros sectores además de los trabajadores y en el cual grupos de diferente extracción social se articulan en un colectivo a partir de una situación de amenaza compartida. De este modo, la militancia pareciera quedar presentada como una "reacción" común frente a la posibilidad de 
perder los derechos conquistados pero agrega: "se quería una justicia social", aparece aquí uno de los términos provenientes de la ideología peronista a los que hacíamos referencia anteriormente para referirse a los objetivos de las acciones llevadas adelante en el marco de su militancia en el PRT. Podríamos considerar que este tipo de alusiones, sumadas a la notable ausencia de referencias explícitas a conceptos vinculados a los contenidos programáticos marxistas del PRT, expresan un rechazo de esta ideología o un débil anclaje de la misma en la conciencia de la entrevistada. Sin embargo, el sentido asociado a la idea de justicia social en el relato nos permite complejizar esta lectura. La noción de justicia social aparece vinculada a lo colectivo, es presentada como una superación de las diferencias sociales que no resulta de la intervención Estatal sino de una lucha en la cual el Estado muchas veces se presenta como antagonista. De este modo, el sentido que Beba atribuye a la noción de justicia social pareciera contradecir uno de los aspectos centrales atribuidos a esa idea desde la ideología peronista: su vinculación a la figura de un Estado capaz de garantizar el equilibrio entre los intereses del capital y los trabajadores a través de la moderación de los excesivos intereses de las clases ${ }^{17}$. En la misma dirección podemos interpretar su anterior afirmación acerca de que "siempre habían renegado de Perón" que en otras partes de la entrevista aparece vinculada fuertemente a la política asumida por el gobierno peronista en la gran huelga azucarera de $1949^{18}$.

Estos elementos parecieran abonar la idea antes planteada acerca de que los procesos de identificación de la entrevistada en el plano políticopartidario se jugaron en un nivel más amplio y más complejo que el de la adscripción racional a los contenidos programáticos de las organizaciones. En este nivel, la capacidad de las ideologías formalmente postuladas y de las prácticas desplegadas por las organizaciones políticas para articularse con las pautas culturales construidas a través de la experiencia de clase se ubica como un aspecto central en el análisis de los procesos subjetivos y colectivos de identificación político-partidarios. Desde esta perspectiva sería posible comprender el sentido de continuidad subyacente en el relato de Beba entre su vida cotidiana, su militancia en el peronismo y su posterior ingreso al PRT en términos de una persistencia de estructuras de sentimiento organizadas en torno a una noción de "nosotros contra otros" que, habilitando una lectura de la realidad en términos de antagonismo social, condensaron en diversas formas de identificación política.

El análisis realizado hasta aquí ha permitido explorar algunos aspectos de la subjetividad de Beba: su visión acerca del proceso de lucha de clases desarrollado en Tucumán durante las décadas de 1960 y 1970, las significaciones atribuidas a su experiencia personal y familiar en ese proceso, y los sentidos atribuidos a su militancia. A través del análisis de su historia de vida hemos podido rastrear la presencia de una tradición contestataria 
configurada en torno a la persistencia de una noción de "nosotros contra otros" construida a lo largo de una experiencia colectiva anclada en condiciones de clase y trasmitida oralmente de generación en generación.

Como fue mencionado, esta tradición opera fuertemente en el relato permitiendo establecer una continuidad entre la propia experiencia y la de las generaciones anteriores cuya base es una percepción de la realidad como el resultado, siempre en devenir, de una confrontación entre grupos opuestos en sus intereses, valores y formas de vida. De este modo, se configura un relato en el cual los sentidos atribuidos a la experiencia histórica construyen, en el mismo movimiento, un posicionamiento identitario de corte contestatario vinculado a la condición obrera.

Este posicionamiento opera en la narración en diferentes niveles íntimamente vinculados entre sí. En un primer nivel, como punto de referencia en la significación de los procesos históricos narrados. Beba nos cuenta una "historia en perspectiva" en el cual los procesos generales son significados en y desde la alusión a una experiencia vital marcada por condiciones de clase y, al mismo tiempo, esos procesos tienen un peso importante en la construcción de sentidos sobre su experiencia subjetiva. De este modo, desde el punto de vista de la entrevistada, su propia historia es más que sólo suya, es parte de la historia de un colectivo más amplio y sólo puede comprenderse a través de la referencia a ese colectivo. De ahí quizás que para hablar de su experiencia subjetiva aluda en la mayoría de los casos a un "nosotros" y utilice pocas veces la primera persona del singular. En este punto, podemos preguntarnos acerca del valor del testimonio de Beba como vía de acceso a la subjetividad obrera de la época, en otras palabras, ¿es la suya una mirada individual o puede ser considerada como representativa de lo colectivo? Sin pretender agotar esta compleja cuestión, consideramos que una $\mathrm{u}$ otra respuesta dependen del punto de partida que adoptemos a la hora de analizar lo social. Si nuestro punto de partida es el individuo, entonces el testimonio de Beba constituye una mirada singular que sumada a muchas otras nos permite el acceso a la subjetividad social de la época. $\mathrm{Si}$, en cambio, entendemos que el punto de partida es lo social y que los sujetos sólo se constituyen como tales a través de las relaciones con otros, entonces el relato se nos presenta como una visión particular de significaciones colectivas construidas en una experiencia compartida. Desde esta perspectiva, es posible pensar que el testimonio de Beba contiene rastros de esas significaciones colectivas y que es, en cierto sentido, representativo de las mismas.

En un segundo nivel, el conjunto de valores, intereses y formas de vida que definen el posicionamiento identitario antes mencionado operan en el relato configurando un sentido de continuidad entre la experiencia cotidiana, la militancia en el PB y su posterior ingreso al PRT. En este sentido, las pautas culturales asumen un lugar central en la explicación de sus opciones 
políticas. Estas opciones aparecen como el resultado de un proceso complejo e irreductible a la adhesión racional con los contenidos programáticos de las organizaciones, en el cual, la capacidad de las mismas para anclar en las estructuras de sentimiento que definen la posición identitaria de la entrevistada adquiere un lugar central. Estos elementos contribuyen además a comprender su particular lectura de los elementos que definen ideológicamente al peronismo y al PRT.

Finalmente, al estructurar una percepción de lo social en términos de antagonismo, el posicionamiento antes mencionado permite establecer una continuidad histórica tanto en los objetivos de las luchas obreras como en las estrategias adoptadas por las clases dominantes. Por esta vía se torna posible una apropiación de la experiencia histórica de la clase que opera como clave de significación del presente $y$, de modo complementario, la construcción de una mirada crítica sobre el pasado que no supone una impugnación de los objetivos de la lucha. En este sentido, constituye una lectura del pasado y del presente que habilita la posibilidad de proyectar el futuro en términos de transformación porque, como dice Beba, "las batallas nunca terminan".

Beba: A veces nos ponemos y les digo "¿sabés lo que hubiese sido si hubiéramos ganado?”... Sí, sí me imagino... Capaz que sean imaginaciones, pero no, creo yo que no. Creo que no, ¿sabés por qué?, porque la gente que estaba en eso... por supuesto que no hacías un contrato con papel, ni con nada... pero creo que todos nos conocíamos los temples y se iba a hacer prevalecer la palabra... Porque antes de que vos digas "bueno, sí, yo estoy con vos" te tienen que decir también... porque ya pensás hasta en eso, pensás en el ganar y en el perder... estaba claro. Incluso te decían "si llegamos a perder no nos lamentemos, no nos desesperemos"... las batallas nunca terminan, tienen continuación de una manera o de otra (...) Entonces la palabra, lo hecho, todo lo que se ha pasado, no ha sido en vano, no ha sido en vano. Porque si nono hubiéramos salido... equivocados, como sea, no importa, pero hemos salido, se ha salido, se ha luchado ${ }^{19}$.

\section{NOTAS}

1 WILLIAMS, Raymond. Marxismo y literatura. Buenos Aires: Las cuarenta, 2009

2 El GIGET es un equipo de trabajo interdisciplinario independiente que desde 2005 viene desarrollando un trabajo orientado a la visibilización del carácter genocida de las prácticas represivas desplegadas en Tucumán durante el Operativo Independencia y la última dictadura militar; a la reconstrucción histórica de las luchas locales a través de la voz de sus protagonistas y al análisis de las formas de memoria actualmente vigentes sobre este proceso 
en las clases populares. Cuenta con el aval del Movimiento Ecuménico por los Derechos Humanos (MEDH) y la Asociación de ex Detenidos-Desaparecidos.

3 Nos referimos a la Alianza Anticomunista Argentina, un grupo paramilitar que actuó entre 1973 y 1976, liderado por José López Rega por entonces a cargo del Ministerio de Bienestar Social. A este grupo se le atribuye el asesinato y la desaparición de más de 700 personas, la mayoría de ellas militantes de organizaciones políticas de izquierda. Diversos estudios plantean que entre sus principales objetivos se encontraba el debilitamiento de los lazos construidos entre el movimiento sindical, el estudiantil, los movimientos barriales y las organizaciones armadas de izquierda.

4 La Comisión Nacional sobre la Desaparición de Personas (CONADEP) fue creada por el Gobierno argentino en 1983 con el objetivo de investigar las violaciones a los derechos humanos producidas durante la última dictadura militar en Argentina. Esta investigación dio origen al Informe "Nuca Más", publicado en septiembre de 1984.

5 El bussismo es una fuerza política nacida bajo el liderazgo de Antonio Domingo Bussi, quien comandó el Operativo Independencia a partir de diciembre de 1975 y fue gobernador de facto de Tucumán entre 1976 y 1977. Con el retorno a la democracia en 1983 fue procesado por delitos de lesa humanidad pero quedó impune por la Ley de Punto Final de 1986. Esto permitió que desde 1987 volviera a la arena política para organizar la fuerza política que lo llevó a la gobernación de Tucumán en las elecciones de 1995. En 2010, luego de la anulación de las leyes de Punto Final y Obediencia Debida fue condenado por la desaparición del ex senador provincial Guillermo Vargas Aignasse. Murió en noviembre de 2011 cumpliendo su pena en prisión domiciliaria.

6 Se refiere a Hilda Guerrero de Molina, activista del sindicato del Ingenio Santa Lucía, asesinada por las fuerzas represivas el 12 de enero de 1967 en el marco de las acciones de protesta obreras contra el cierre de los ingenios azucareros.

7 Entrevista con Beba, Famaillá, Tucumán. Entrevistada por GIGET en febrero de 2006. Archivo Testimonial sobre el Operativo Independencia y la dictadura militar en Famaillá. Entrevista núm. 24

8 La entrevistada se refiere a la ciudad de Famaillá

9 En referencia a una protesta protagonizada por empleados de la Municipalidad de Famaillá en 2005

10 Entrevista con Beba, 2006 (Op. Cit)

11 CRENZEL, Emilio. El Tucumanazo. Buenos Aires: UNT, Facultad de Filosofía y letras, 1997;Pucci, Roberto. Historia de la destrucción de una provincia. Tucumán 1966. Buenos Aires: Ediciones del pago chico, 2007.

12 Entrevista con Beba, 2006 (Op. Cit)

13 Entrevista con Beba, Famaillá, Tucumán. Entrevistada por GIGET en julio de 2012.

14 Entrevista con Beba, 2012 (Op. Cit.)

$15 \mathrm{La}$ entrevistada se refiere a la migración de trabajadores rurales tucumanos en búsqueda de empleos temporarios en las cosechas estacionarias de otras provincias. En la mayoría de los casos se trata de empleos informales, con ingresos inferiores a los que se considera de subsistencia.

16 Entrevista con Beba, 2012 (Op. Cit.)

17 JAMES, Daniel. Resistencia e Integración. El peronismo y la clase trabajadora argentina, 
1946-1976. Buenos Aires: Siglo veintiuno, 2006, pág. 131

18 Nos referimos a la huelga general impulsada por la FOTIA y la FEIA (Federación de Empleados de la industria azucarera) el 14 de octubre y el 24 de noviembre de 1949. La acción fue llevada a cabo para exigir un aumento salarial del 100\%. Durante el trascurso de la misma la Secretaría General del trabajo declaró ilegal e intervino ambos sindicatos y anuló su personería gremial; los locales de la FOTIA fueron cerrados y sesenta dirigentes fueron encarcelados. Tras un mes y medio de huelga la FOTIA levantó la medida de fuerza desgastada por las severas privaciones económicas provocadas por la paralización. A los pocos días de finalizada la huelga Perón anunció un aumento salarial del $60 \%$ y atacó a los dirigentes de la huelga acusándolos de traición y sabotaje. Muchos militantes peronistas fueron desplazados de sus cargos y expulsados del Partido Peronista. (Romano, Graciela del Valle: Benito, Azúcar y Sangre. FOTIA y la huelga azucarera de 1959, Buenos Aires: edición del autor, 2009; Salas, Ernesto. Uturuncos. El origen de la guerrilla peronista. Buenos Aires: Biblos, 2003)

19 Entrevista con Beba, 2012 (Op. Cit.)

Artigo recebido em outubro de 2015. Aceito em dezembro de 2015. 